\title{
Effects of Disaster Management Programs on Individuals' Preparedness in Mount Merapi
}

\author{
Kazuhiko Otani \\ Yachiyo Engineering Consultant Ltd. Co., Tokyo, JAPAN \\ otani@intl.yachiyo-eng.co.jp \\ Djoko Legono \\ Department of Civil and Environmental Engineering, Universitas Gadjah Mada, Yogyakarta, INDONESIA \\ djokolegono@yahoo.com \\ Suseno Darsono \\ Civil Engineering Department, Diponegoro University, Semarang, INDONESIA \\ sdarsono@hotmail.com \\ Suharyanto \\ Civil Engineering Department, Diponegoro University, Semarang, INDONESIA \\ suharyanto20@yahoo.co.id
}

\begin{abstract}
Disaster management to mitigate or avoid impacts of hazards by reducing vulnerability has been conducted in Mount Merapi since 1969. Vulnerability introduced since 1980s has two main characteristics, such as physical vulnerability (i.e., impacts of hazards) and social vulnerability (i.e., composite characteristics including social, economic and environmental factors). As regulations in Indonesia, i.e. Law of Republic Indonesia No. 24 Year 2007, emphasizes the community involvement in disaster management, individuals or groups of individuals have significant roles in reducing social vulnerability. To promote the community involvement effectively in disaster management, this research hypothesized nine relationships between disaster management programs to assess effects of disaster management programs on the community involvement, such as individuals' preparedness. Since disaster management programs are not measurable quantitatively, variance-based partial least squares structural equation modeling (PLS-SEM) was applied to test hypothesized causal relationships between the programs. As a result, all nine hypotheses were substantiated. The model revealed that individuals' preparedness is significantly influenced by emergency logistics and financial aid through self-efficacy, and contingency plans affect reconstruction significantly and successively reconstruction affects rehabilitation.
\end{abstract}

Keywords: disaster management, vulnerability, individuals’ preparedness, PLS-SEM

\section{INTRODUCTION}

Mount Merapi, literally a fire mountain in Indonesia, is an active stratovolcano located on the border between Central Java Province and Yogyakarta Special Province in Indonesia. It is the most active volcano in Indonesia and has erupted regularly. Major eruptions in the last 100 years occurred in 1920, 1930, 1954, 1961, 1969, 1976, 1994, 2006 and 2010. Eruptions of Mount Merapi is characterized by (1) pyroclastic flows due to collapse of the lava dome or lava tip leaving the loose volcanic deposit on the slope of Mount Merapi; (2) volcanic ash fall; and (3) debris flows in the following rainy seasons after eruptions (Directorate General of Water Resources (DGWR), 2001). A large amount of erupted materials in upstream left by pyroclastic flows moves to downstream as debris flows triggered by rainfall.
Yogyakarta city extends in the south foot of Mount Merapi, and there are the world heritages, such as Prambanan and Borobudur temples. Considering the significance of those areas, the Government of Indonesia has made efforts in disaster management continuously by applying structural measures (i.e., sabo dams for debris flow control) and non-structural measures (i.e., early warning system and evacuation system) since 1969 (DGWR, 2001).

The last eruption of Mount Merapi occurred in October and November 2010. According to National Disaster Management Agency (BNPB), the 2010 eruption caused 386 fatalities, 400,000 evacuees, and loss of 3,300 houses/buildings due to pyroclastic flows and continuous debris flows. One of the main reasons for these damages is a hazardous event (i.e., eruptions and debris flows) per se. Besides, there are 
two reasons considered. One is that the scale of eruptions exceeded the design scale so that sabo dams could not prevent debris flow disasters, and second is a delay in evacuation of some communities despite the immediate issue of evacuation order by the government. These two reasons imply the necessity of different approach for effective disaster management as well as conventional structural and non-structural measures. The notion of Oliver-Smith (1999) that disasters occur in societies but not in nature implies that disasters are not only hazardous events but also social consequences of the events. Thus, the society or community is a key concern for the effective disaster management.

The sand mining in river courses (i.e., dredging pyroclastic deposits consisting of sand and gravel) is conducted extensively in Mount Merapi. DGWR (2009) identifies sand mining issues, such as severe riverbed degradation resulting in collapses of sabo dams and dikes, damages of road and bridges, environmental degradation, and damages to tourism resources. The result of participatory rural appraisal (PRA) conducted in DGWR (2009) explained that $35 \%$ of respondents suggested an involvement of community near a quarry in the sand mining management. This community's proactive perception implies potential of the community involvement in the disaster management.

The term disaster is popular and used as a common phrase; however, its definition quite varies depending on scientific domains. The purposes of devising the definitions vary depending on a concept or an area of study and there is no single content of definitions (Perry, 2007). An assessment of physical impacts of physical agents and or phenomena is main concern to deal with disasters in perspective of civil engineering and geophysics. On the other hand, in social and behavioral sciences, disasters are assumed as social consequences of the physical impacts, emphasizing social rather than physical. Therefore, the definition may vary also depending on who requires the definition. For example, the government needs the mandated definitions of disaster to determine its clear tasks with criteria in the disaster risk management (Perry, 2007). Vulnerability that is a concept evolved out of the social science was introduced as a response to the hazard centered perspective of disaster risk in the 1970s and vulnerability has been used as an alternative perspective for risk reduction by replacing the hazard centered perspective since the $1980 \mathrm{~s}$ (Birkmann, 2006). The current concept of vulnerability has shifted from a primary analysis of physical aspects to a broad multidisciplinary analysis (Birkmann, 2006).
Traditional disaster management that focuses the preparation and operation capacities for response to hazardous event in short-term or aftermath has been dominant in many places; however, a holistic approach emphasizing vulnerability and risk has emerged (United Nations International Strategy for Disaster Reduction (UNISDR), 2004). Since an objective of disaster management is to reduce risk to human life and social systems necessary for livelihood (O'Brien et al., 2006), a holistic approach of disaster management involves various programs to deal with physical, social, economic and environmental factors that exist continuously in the society, instead of dealing with the short-term emergency conditions. Becker (2009) notes that disaster risk involves factors from all spheres of the society and those factors are interdependent. It implies that various disaster management programs interact with one another. Since a project for disaster risk reduction without understanding interdependencies of the factors generates sub-optimization (i.e., a change in one factor does not produce the desired outcome in the project) and problems with monitoring and evaluation of the real effects of a change on the whole project, to acknowledge interdependencies of factors in the project is a key requirement to achieve a project goal successfully in disaster risk reduction (Becker, 2009). Thus, the relationships between disaster management programs in the pre-disaster period, during disaster and post-disaster period need to be identified to contribute to promoting a holistic disaster management in the long term.

The government's initiative mostly facilitates to mitigate vulnerability by formulations of contingency plans, construction of disaster prevention facilities such as sabo dams, installation of early warning systems, emergency responses, recovery of physical infrastructures, rehabilitation and so on. Meanwhile, although the government has significant roles on mitigation of vulnerability, the community involvement is considered a key to reducing vulnerability. To promote the community involvement effectively in disaster management, this research aimed to identify interactions between disaster management programs in Mount Merapi so that effects of disaster management programs on the community involvement, such as the community development and individuals' preparedness, could be identified. Thus, this research hypothesized the following nine relationships between disaster management programs to develop a model to explain causal links between disaster management programs in Mount Merapi. Since disaster management programs are not measurable quantitatively, variancebased partial least squares structural modeling (PLS- 
SEM) was applied to test the hypothesized causal relationships.

\subsection{Emergency Logistics and Financial Aid, and Rehabilitation}

According to Bowersox and Closs (1996), Ballou (1999), Johnson et al. (1999), logistics is the process of planning, implementing, and controlling the efficient, effective flows and storage of goods, services and related information from the point of origin to the point of consumption for the purpose of conforming to customers' requirements at the lowest total cost. Therefore, emergency logistics and financial aid were viewed as a process of moving financial aid and goods from point $\mathrm{A}$ to $\mathrm{B}$ by planning, managing, and controlling the efficient flows to fulfill the urgent needs of specific people under emergency circumstances. On the other hand, rehabilitation is to repair and/or recover all aspects of public and social services to the sufficient level (UU No. 24/2007: Law No. 24/2007 in Indonesia). Thus, rehabilitation, particularly in the short-term after the onset of a disaster, requires emergency logistics and financial aid as resources of rehabilitation. Hence, the hypothesis 1 was that emergency logistics and financial aid [LOG] had a positive effect on rehabilitation [REH].

\subsection{Emergency Logistics and Financial Aid, Self- Efficacy and Individuals' Preparedness}

The social-cognitive preparation model proposed by Paton (2003) explains that people's intentions to prepare for hazardous events are determined by response efficacy and self-efficacy. While response efficacy describes people's perception of the available resources, such as time, skill, finance, physical resources, social networks (Paton, 2003), self-efficacy describes individuals' appraisal of what they are capable of performing (Paton and Johnston, 2001). Paton et al. (2010) address that if a disaster occurs, people's ability to cope with, adapt, and recover promptly and effectively will strongly be influenced by the degree to which they have developed the resources and competencies required to do so prior to the onset of a disaster. Therefore, emergency logistics and financial aid affect self-efficacy. Hence, the hypothesis 2 was that emergency logistics and financial aid [LOG] had a positive effect on selfefficacy $[\mathrm{EFI}]$.

Preparedness is the knowledge and capacities to effectively anticipate, respond to, and recover from, the impacts of hazard (UNISDR, 2009). Therefore, individuals' preparedness can be viewed as the readiness of the individual to cope with a disaster. Since preparation for hazardous events by individuals depends on their intention formed by self-efficacy and response efficacy (Paton, 2003), hypothesis 8 was that self-efficacy affected individuals' preparedness positively.

\subsection{Contingency Plans, Reconstruction and Rehabilitation}

Since recovery is restoring or improving the social structures within communities suffered from disaster by underlining sustainable development with better conditions to avoid future disaster risk (UNISDR, 2017), recovery consisting of rehabilitation and reconstruction in the post-disaster period (UU No. 24/2007) requires contingency planning in the predisaster period. Federal Emergency Management Agency (FEMA) (1998) provides a good model and reasonably detailed example of a contingency plan on a regional basis. The plan consists of several items, such as estimated damage to various types of structures by hurricanes of varying strengths, initial job losses, population displacement, and similar projections. This FEMA approach explains that recovery needs a contingency plan prior to the onset of a disaster.

To attain rehabilitation requires reconstruction (i.e., to rebuild all infrastructures and social arrangements). It implies that rehabilitation is influenced by reconstruction. Without infrastructures, rehabilitation of disaster-affected areas will remain very slow and limited. Since the distribution of aid and goods require infrastructure in a rehabilitation phase, reconstruction needs to be conducted first. Hence, two hypotheses were conceived. One (the hypothesis 3) was that contingency plans [PLN] had a positive effect on reconstruction [REC], and another (the hypothesis 6) was that reconstruction had a positive effect on rehabilitation.

\subsection{Information and Coordination, and Community Development}

Comfort et al. (1999) suggest multi-way information exchange systems to increase the capacity of communities to make available and share timely accurate information about risk for self-organization of disaster management, and training and capacity building to facilitate local initiatives in order to reduce vulnerability and increase community participation in disaster management. Besides, Paton and Johnston (2001) underline the development of communication strategies with the inclusion of the social psychological factors so that people can adapt information provided and can act as recommended because communication effectiveness for public campaigns can be influenced by beliefs of people based on the existing knowledge. The communication 
strategies require developing effective messages in the context of diversity of vulnerable groups by defining the relationships between vulnerable groups and effects of hazardous events and successively adapting information for each group (Paton and Johnston, 2001). Hence, the hypothesis 4 was that information and coordination had a positive effect on community development. Besides, community development was viewed in this research as efforts of a community to manage recovery works, social order, and the environment through facilitation by the government and Non-Government Organizations (NGOs).

\subsection{Disaster Management Capacity and Community Development}

Disaster risk management to avoid, lessen or transfer the adverse impacts of hazards is composed of efforts such as administrative directives, organizations, and measures for prevention and mitigation (UNISDR, 2009). As measures for prevention and mitigation, the Government of Indonesia has applied early warning system and evacuation system in Mount Merapi since 1969 (DGWR, 2001), and the series of evacuation operations, such as alert, decision of emergency status and allocation of people to evacuation shelters are conducted in line with disaster risk management. Thus, viewing capacity in terms of the government initiatives, disaster management capacity was defined as accessibility of the community to policy, and technical and institutional supports by relevant disaster management agencies. In accordance with the definition, the hypothesis 5 that disaster management capacity [CAP] had a positive effect on Community development [CDV] was conceived.

\subsection{Community Development and Rehabilitation}

According to UU No. 4/2007, rehabilitation aims not only to recover all aspects of public and social services but also to improve economic conditions by empowering the community, to improve the resilience of the community by capacity building and public campaign, and to strengthen social capital by provision of entertainment facilities. Bhandari et al. (2010) reveal that social capital built over time in a community through ritual events contributes to resilience. Besides, Thomas's (1995) effective decision model of public involvement shows that in most situations, the participation of the community in decision-making is crucial to any effective approach to mitigation. Hence, it was hypothesized that community development [CDV] had a positive effect on Rehabilitation [REH] (the hypothesis 7).

\subsection{Rehabilitation and Individuals' Preparedness}

Most people's goal in rehabilitation is to restore households, businesses, and government activities to the normal patterns that existed before the disaster struck. To get the normalcy, people typically assume that buildings and infrastructure must be restored as they were before the disaster. However, it is increasingly understood that restoring the community to its previous condition will also reproduce its previous hazard vulnerability. Consequently, a disaster resilient community learns from experiences as to which areas of the community have an excessive level of hazard exposure. It also identifies the buildings and infrastructure that have inadequate designs, construction methods, and construction materials. Hence, based on a disaster that happened previously, individuals who live in a disaster-prone area should learn from the past to be prepared for possible upcoming disasters. In accordance with the discussion above, the hypothesis 9 that Rehabilitation [REH] has a positive effect on individuals' preparedness [PRE] was conceived.

\subsection{Hypothesized Relationships of Disaster Management Programs}

Figure 1 shows the hypotheses as discussed and formulated based on various aforementioned studies, and also shows the structural model that represents nine latent variables and relationships (i.e., paths) between the variables. Since reconstruction, rehabilitation and community development are composed of many relevant factors to disaster management, Hierarchical Component Models (HCMs) were applied. While the higher order variable captures the more abstract entity, the lower order variables capture the sub-dimensions of the abstract entity. HCMs make PLS-SEM model more parsimonious and easier to grasp by reducing the number of relationships in the structural model (Hair et al., 2013). Thus, reconstruction, rehabilitation, and community development were 2nd-order variables measured by 1 st-order variables. 


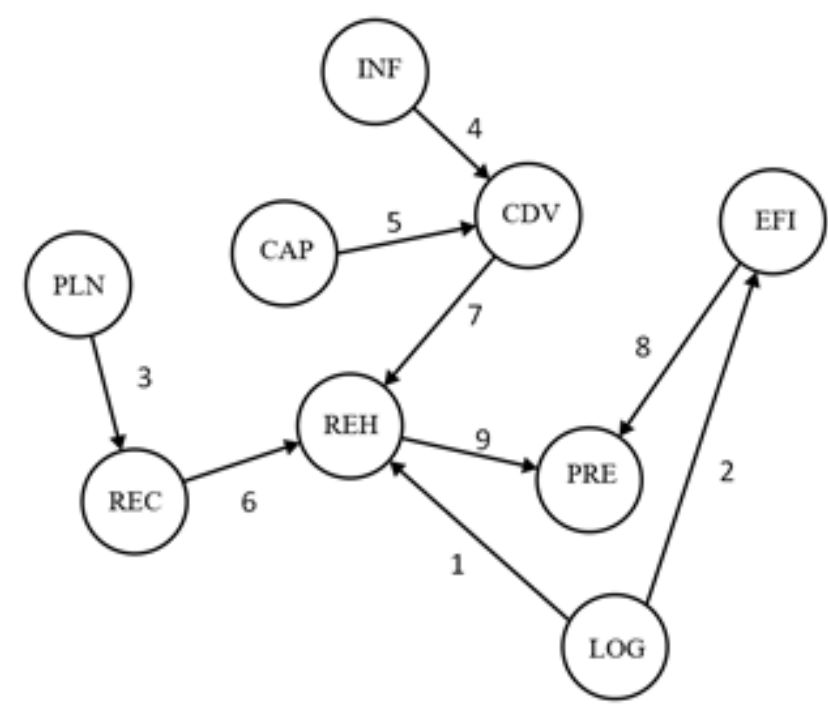

where:

a) REC is a second-order latent variable for post-disaster reconstruction,

b) REH is a second-order latent variable for post-disaster rehabilitation,

c) $\mathrm{CDV}$ is a second-order latent variable for community development,

d) CAP is a latent variable for disaster management capacity,

e) PLN is a latent variable for contingency plans,

f) LOG is a latent variable for emergency logistics and financial aid,

g) INF is a latent variable for information and coordination,

h) EFI is a latent variable for self-efficacy, and

i) PRE is a latent variable for individuals' preparedness.

Figure 1. Hypotheses on Disaster Management

These three composite programs (i.e., 2nd-order variables) were measured by related factors (i.e., 1storder variables). Reconstruction was measured by four 1st-order variables, such as rebuilding of homes and public facilities, materials for rebuilding, design, and disaster prevention facilities. Rehabilitation was measured by five 1st-order variables, such as counseling, training, entertainment recovery, economic recovery, and education. Community development was measured by four 1st-order variables, such as community participation, restructuring of social structure, environmentally friendly families, and social empowerment.

\subsection{Measurement of Disaster Management Programs}

UNDP (2004) and Bollin et al. (2003) introduce the disaster risk index (DRI) and the community-based disaster risk index (CBDRI), respectively, to measure vulnerability and risk. These attempts provide measurements of vulnerability and other disaster terms by scores of indices for relative comparisons. However, they are not able to depict the relationships among disaster terms. Schneiderbauer and Ehrlich (2006) note that a number of qualitative parameters that are highly relevant to vulnerability assessment, such as disaster management, are difficult to be described. It implies that disaster management programs in this research are latent variables (i.e., not observable), and require proxies to measure them. Structural Equation Modeling (SEM) enables researchers to incorporate unobservable variables measured indirectly by indicator variables that are observable. There are two types of SEM, covariancebased SEM (CB-SEM) and variance based partial least squares SEM (PLS-SEM). While CB-SEM is primarily used to confirm or reject theories, PLS-SEM is mainly utilized to develop theories in exploratory research (Hair et al, 2013). PLS-SEM is appropriate to research focusing on prediction and theory development because it estimates the hypothesized relationships maximizing explained variance through OLS regression (Henseler et al., 2012).

There were three reasons to apply PLS-SEM in this research. First, this research aimed to examine the exploratory predictions to identify as to whether there were causal relationships between the latent variables. PLS-SEM is very suitable for prediction purposes because it will maximize endogenous latent variables' explained variances and minimize the measurement errors. Second, PLS-SEM can be run using a small sample size. Since this research drew a sample from respondents who had been involved and affected by the process of disaster management, the low response in questionnaire surveys was anticipated. Third, the assumptions used in SEM-PLS are relatively less stringent than those in CB-SEM.

There are previous studies applying CB-SEM to disaster management, such as psychological recovery process (Tatsuki et al., 2004), people's perception on administrative and self-help measures (Hashiue et al., 2003), community involvement in environment improvement (Fukushima and Matsumoto, 2007), and effects of social capital on resilience of the community (Bhandari et al., 2010). These previous studies focus the specific scopes in disaster management. On the contrary, this research viewed disaster management in the context of broad scope considering nine programs in the pre-disaster, disaster and post-disaster periods.

\section{METHOD}

This research was essentially a quantitative exploratory study, which attempted to investigate the relationships between disaster management programs 
(i.e., latent variables) in the post-disaster period. Indicator variables to assess latent variables were quantified by questionnaire surveys with five-point Likert scales. In addition to quantitative data through questionnaire surveys, qualitative data were collected through in-depth interviews.

\subsection{Data Collection}

This research utilized data collected from questionnaire surveys with five-point Likert scales in Mount Merapi area in order to measure indicator variables pertaining to an objective latent variable (i.e., disaster management program). For the statistical test of PLS-SEM, there is a minimum required sample size to detect minimum $\mathrm{R}^{2}$ (i.e., coefficient of determination) values of $0.10,0.25,0.50$, and 0.75 for significance levels of $1 \%, 5 \%$, and $10 \%$, respectively (Cohen, 1992). Since a 5\% significance level common in the social science was applied to the research, a minimum sample size of 144 was required to detect a very weak effect (minimum $\mathrm{R}^{2}$ values of 0.10 ). As a precautionary procedure, however, a sample size of 192 was collected. In addition to questionnaire surveys, in-depth interviews were conducted to identify the preset post-disaster conditions, such as achievement of mandated tasks and related issues of disaster management agencies, and preparation for disaster risk by village authorities.

Five government agencies, one NGO and, nine villages were selected for questionnaire surveys and in-depth interviews. Five government agencies consisted of two central government agencies, such as the Serayu-Opak River Basin Management Agency (Balai Besar Wilayah Sungai Serayu Opak) and the Sabo Research Center (Balai Sabo), and three local government agencies in Sleman Regency, such as the Regional Agency for Disaster Management (Badan Penanggulangan Bencana Daerah), the Office of Public Works and Housing (Dinas Pekerjaan Umum dan Perumahan), and the Regional Development Planning Agency (Badan Perencanaan Pembangunan Daerah). One NGO selected was the Disaster Risk Alleviation Forum (Forum Pengurangan Risiko Bencana). Each agency appointed five respondents to questionnaire surveys and two respondents to in-depth interviews in response to requests. The number of respondents from these agencies in total was 30 for questionnaire surveys and 12 for in-depth interviews.

The number of respondents from each village level organization, such as village offices, disaster response teams (Taruna Siaga Bencana), and other nongovernmental organizations, was set 18 for questionnaire surveys and two for in-depth interviews, assuming that village-level organizations had knowledge about real circumstances because they were directly impacted by a disaster and also lived in disaster-prone areas. Nine villages selected in Sleman Regency where the 2010 Mount Merapi eruption severely damaged were Hargobinangun, Purwobinangun, Girikerto, Wonokerto, Argomulyo, Glagahharjo, Wukirsari, Kepuhharjo, and Umbulharjo. Thus, the total respondents from villages were 162 for questionnaire surveys and 18 for indepth interviews.

As a result, a sample size of questionnaire surveys and in-depth interviews conducted were 192 and 30, respectively. These surveys were conducted from December 7, 2016, to January 7, 2017. Forty-five indicator variables were assigned to measurement of 9 latent variables (i.e., the measurement model). Therefore, each questionnaire survey was composed of 45 questions (i.e., indicator variables) with fivepoint Likert scales.

\subsection{Analysis Method}

Data analysis was conducted through several steps. First, a path model estimation was conducted using Smart PLS 2.0 M3 to generate three key results: (1) outer loadings for the measurement model; (2) path coefficients for the structural model; and (3) $\mathrm{R}^{2}$ values of endogenous latent variables. Subsequently, the second step was to determine how well the theory fits the data.

The hypothesized relationships are expressed in the following equations.

$$
\begin{aligned}
& \mathrm{PRE}_{\mathrm{i}}=\beta_{1} \mathrm{REH}_{\mathrm{i}}+\beta_{2} \mathrm{EFI}_{\mathrm{i}}+\varsigma_{1 \mathrm{i}} \\
& \mathrm{EFI}_{\mathrm{i}}=\beta_{3} \mathrm{LOG}_{\mathrm{i}}+\varsigma_{2 \mathrm{i}} \\
& \mathrm{CDV}_{\mathrm{i}}=\beta_{4} \mathrm{CAP}_{\mathrm{i}}+\beta_{5} \mathrm{INF}_{\mathrm{i}}+\varsigma_{3 \mathrm{i}} \\
& \mathrm{REH}_{\mathrm{i}}=\beta_{6} \mathrm{REC}_{\mathrm{i}}+\beta_{7} \mathrm{CDV}_{\mathrm{i}}+\beta_{8} \mathrm{LOG}_{\mathrm{i}}+C_{4 \mathrm{i}} \\
& \mathrm{REC}_{\mathrm{i}}=\beta_{9} \mathrm{PLN}_{\mathrm{i}}+\varsigma_{5 \mathrm{i}}
\end{aligned}
$$

where:

a) $\mathrm{REC}_{\mathrm{i}}$ is a second-order latent variable for postdisaster reconstruction,

b) $\mathrm{REH}_{\mathrm{i}}$ is a second-order latent variable for postdisaster rehabilitation,

c) $\mathrm{CDV}_{\mathrm{i}}$ is a second-order latent variable for community development,

d) $\mathrm{CAP}_{\mathrm{i}}$ is a latent variable for disaster management capacity,

e) $\mathrm{PLN}_{\mathrm{i}}$ is a latent variable for contingency plans,

f) $\mathrm{LOG}_{\mathrm{i}}$ is a latent variable for emergency logistics and financial aid, 
g) $\mathrm{INF}_{\mathrm{i}}$ is a latent variable for information and coordination,

h) $\mathrm{EFI}_{\mathrm{i}}$ is a latent variable for self-efficacy,

i) $\mathrm{PRE}_{\mathrm{i}}$ is a latent variable for individuals' preparedness,

j) $\beta_{\mathrm{i}}$ is a regression relation between endogenous latent variables, and

k) $C_{\mathrm{i}}$ is an error term for endogenous latent variables.

\section{RESULTS AND DISCUSSION}

\subsection{Profiles of Respondents for Questionnaire Surveys}

This research collected data through questionnaire surveys to 192 respondents across nine villages affected by the 2010 Mount Merapi eruption, five government agencies in charge of the disaster management and one NGO for emergency response during the disaster. The respondents for questionnaire surveys were classified in accordance with respondents' social status. As a result, the class of citizens was the largest (140 respondents or $72.92 \%$ ), followed by governmental institutions ( 25 respondents or $13.02 \%)$, administrative officers at the village level (22 respondents or $11.46 \%$ ), and NGO members (5 respondents or $2.60 \%$ ).

Demographic characteristics observed were, namely years of dwelling in the research area, gender, age, educational background, and job tenure. With regard to the period of dwelling, 136 respondents $(70.83 \%)$ had been living in Yogyakarta Special Region for more than ten years, whereas 56 respondents (29.17\%) had been living in Yogyakarta Special Region for less than ten years. In summary, it was reasonable to say that at least $70.83 \%$ of respondents had experienced before, during and after the 2010 Mount Merapi eruption. Meanwhile, a sample of 83 male respondents and 109 female respondents were obtained during the survey. Respondents were mostly ranged over 20 years old, and the working population whose ages were between 20 and 60 years old were rated at $86.47 \%$. Subsequently, 91 respondents $(47.40 \%)$ attained a high school level, whereas 45 respondents $(23.44 \%)$ had completed a tertiary education (a bachelor's or a master's degree). Accordingly, the respondents were considered capable of comprehending as well as completing the survey properly.

\subsection{Descriptive Statistics}

As the main variables of interest in this research, perception scores of three 2nd-order variables and six variables without order are summarized in Table 1. Perception scores were the results of mean averaging values of indicator variables that were obtained through the questionnaire surveys. Since the fivepoint Likert scales were applied to the questionnaire surveys with 1 being strongly disagreed and 5 being strongly agreed, a 4.0 cut-off basis (i.e., a score of agree) was used to evaluate each variable score.

Table 1. Perception Indices of Nine Latent Variables

\begin{tabular}{ll}
\hline Latent Variable & Average \\
\hline REC (reconstruction) ${ }^{*}$ ) & 3.94 \\
REH (rehabilitation) ${ }^{*}$ & 3.81 \\
CDV (community development) ${ }^{*}$ & 3.96 \\
CAP (disaster management capacity) & 4.02 \\
PLN (contingency plans) & 3.55 \\
LOG (emergency logistics \& financial & 3.53 \\
aid) (information \& coordination) & 3.70 \\
INF (inf & 3.58 \\
EFI (self-efficacy) & 3.90 \\
PRE (individuals' preparedness)
\end{tabular}

*): 2nd order latent variables

Disaster management capacity [CAP] scored the highest rating (4.02), where this variable is mainly concerned over the accessibility of the community to policy, technical, and institutional support by the related disaster management agencies that mostly belong to the government. Even though the respondents perceived that disaster management by the government initiative had been set well, enhancement is surely necessary because of the large fatalities in the 2010 Mount Merapi eruption.

Other eight variables, which scores were lower than the cut-off basis, also require significant improvement. Emergency logistics and financial aid [LOG] had the lowest rating (3.53). It implies that the government needs to keep allocating sufficient amount of budget for affected communities. The variable whose score was the second lowest (3.55) was contingency plans [PLN], indicating that many stakeholders still failed to understand the contingency plans for disaster management. Therefore, there is a need for more comprehensive socialization. The third lowest score (3.58) was self-efficacy [EFI]. It implies that communities find a severe difficulty rebuilding their homes in the post-disaster period.

\subsection{Relationships between Disaster Management Programs}

The disaster management model with an application of PLS-SEM was tested using SmartPLS 2.0 M3 and SPSS Statistics. The results of testing the measurement model met all required criterion, such as internal consistency reliability, indicator reliability, convergent validity and discriminant validity. Besides, the structural model was evaluated in terms of the model's predictive capabilities and the relationships 
between latent variables, and it confirmed no problem in collinearity, size and significance of path coefficients, and predictive relevance. Although coefficients of determination (i.e., $\mathrm{R}^{2}$ ) were relatively weak resulting in relatively small impacts (i.e., $\mathrm{f}^{2}$ ) and weak effect size (i.e., $\mathrm{q}^{2}$ ) of exogenous latent variables to endogenous latent variables, the test results explained that the model was significant, relevant and predictable.

The test for size and significance of path coefficients evaluated whether the hypothesized relationships were significant and had the desired directions. The test result explained that the path coefficients in Table 2 were statistically significant at $1 \%$ level. In general, a path coefficient of +1 represents a strong positive relationship. The closer the estimated coefficient is to 0 , the weaker is the relationship. Thus, although the strength of relationships varied, the hypothesized relationships between disaster management programs were confirmed valid.

Table 2. Path Coefficient Results

\begin{tabular}{lll}
\hline Hypothesis & Path & Path Coefficient \\
\hline 1 & LOG $\rightarrow$ REH & 0.18 \\
2 & LOG $\rightarrow$ EFI & 0.47 \\
3 & PLN $\rightarrow$ REC & 0.38 \\
4 & INF $\rightarrow$ CDV & 0.37 \\
5 & CAP $\rightarrow$ CDV & 0.25 \\
6 & REC $\rightarrow$ REH & 0.48 \\
7 & CDV $\rightarrow$ REH & 0.21 \\
8 & EFI $\rightarrow$ PRE & 0.40 \\
9 & REH $\rightarrow$ PRE & 0.21 \\
\hline
\end{tabular}

Significance level: $1 \%$

The results showed important findings on what variables that were more critical to enhancing the performances of other latent variables. First, reconstruction [REC] was positively influenced by contingency plans [PLN]. It implies that the government should have well-prepared contingency plans to have good performances of reconstruction. Second, reconstruction affected rehabilitation $[\mathrm{REH}]$, and moreover, its path coefficient was the largest among other variables that affected rehabilitation. Thus, the path $[\mathrm{PLN} \rightarrow \mathrm{REC} \rightarrow \mathrm{REH}]$ was very crucial.

Third, community development [CDV] was positively influenced by information and coordination [INF], which was the largest among variables that affected community development, implying that the government needed to strengthen its coordination and information exchanges with the lowest level of administrative area (i.e., village) to facilitate effective community development.
Fourth, emergency logistics and financial aid were the only variables in the model that affected self-efficacy [EFI]. Among all variables that had been examined; however, its path coefficient was moderate. This suggested that the government had to increase its emergency logistics and financial aid, which conformed to the in-depth interview results. Fifth, self-efficacy had a major influence on individuals' preparedness [PRE]. Hence, the path $[\mathrm{LOG} \rightarrow \mathrm{EFI} \rightarrow \mathrm{PRE}]$ was also very important to be considered by the government.

While exogenous latent variables are constructs to explain other constructs in a model, endogenous latent variables are constructs to be explained by other constructs in a model. Thus, there were five endogenous latent variables in the model. $\mathrm{R}^{2}$ (i.e., a measure of the model's predictive power) is summarized in Table 3. In general, all $\mathrm{R}^{2}$ except rehabilitation explained the weak predictive power. Rehabilitation's variance was explained at medium by two exogenous latent variables, logistics and financial aid, and reconstruction.

Table 3. $\mathrm{R}^{2}$ Results

\begin{tabular}{ll}
\hline Endogenous Latent Variables & $\mathrm{R}^{2}$ \\
\hline CDV (community development) & 0.28 \\
EFI (self-efficacy) & 0.22 \\
PRE (individuals' preparedness) & 0.23 \\
REC (reconstruction) & 0.15 \\
REH (rehabilitation) & 0.41 \\
\hline
\end{tabular}

Since endogenous latent variables in this research are abstract concepts, relatively weak variance explanation is actually reasonable. For instance, reconstruction [REC] that had the lowest $\mathrm{R}^{2}$ surely could not be merely explained by contingency plans [PLN]. There are many factors that cannot be measured from the theoretical or practical view. Despite those limitations, this research was still able to generate significant results that could lead to further research in the future. Besides, the judgment of $\mathrm{R}^{2}$ varies across studies and a value as high as 0.20 could be considered high (Hair et al., 2011; Henseler et al., 2009). According to Hair et al. (2014), $R^{2}$ value is tolerable as long as it exceeds the threshold of 0.10 .

\section{CONCLUSION AND SUGGESTION}

\subsection{Conclusion}

Upon conducting an analysis on individual perception about the current level of disaster management in Mount Merapi, only disaster management capacity scored slightly above the cut-off basis (4.02). It implied that people perceptions on the government initiatives to provide accessibility of the community to 
policy, technical, and institutional supports were good. Meanwhile, emergency logistics and financial aid variable showed the lowest score. The results of in-depth interviews with six agencies also explained issues related to emergency logistics and financial aid. Village officers revealed that the evacuation shelters should have been supported by the accessible supply of logistics and reliable transportation that, in fact, were still poor. Besides, the Regional Agency for Disaster Management in Sleman Regency noted the necessity to improve its management of logistics supply. The disaster management model with an application of PLS-SEM indicated that the path $[\mathrm{LOG} \rightarrow \mathrm{EFI} \rightarrow \mathrm{PRE}]$ was significant. It implied that self-efficacy (i.e., a personal belief in the ability to deal with particular circumstance) could be promoted by appropriate emergency logistics and financial aid and successively individuals' preparedness was largely affected by self-efficacy. Thus, the government is recommended to strengthen emergency logistics and financial aid.

A myriad of tests on the measurement and structural models proved the model's reliability and validity, resulting in substantiating all nine hypotheses in this research. The model also showed important findings on what variables that were more critical to enhancing the performances of other latent variables. In addition to the path $[\mathrm{LOG} \rightarrow \mathrm{EFI} \rightarrow \mathrm{PRE}]$, the path $[\mathrm{PLN} \rightarrow \mathrm{REC}$ $\rightarrow \mathrm{REH}]$ was found very important to be considered by the government. The path implied that rehabilitation to recover all aspects of public and social services needed urgent reconstruction of infrastructures in areas suffered from disaster and well preparation of contingency plans was necessary to achieve urgent reconstruction. The model also underlined that information sharing with the community was a key to the community development.

\subsection{Suggestion}

This research provides benefits to the government officials at different levels and to the society. From the findings, the model can identify how people perceive the government's performance level pertaining to disaster management programs. Accordingly, the model facilitates the government to know what programs need to be strengthened to improve not only individuals' preparedness but also overall disaster management programs.

As place vulnerability is composed of physical or biophysical vulnerability and social vulnerability (Cutter, 1996), disaster management contributing to reduction of vulnerability needs a multidisciplinary approach underlining individuals' preparedness and community involvement in disaster management.
Although social vulnerability has been ignored due to the difficulty in quantifying it (Cutter et al., 2003), disaster risk reduction cannot be attained only by the hazard-centered perspective. Since key stakeholders to reduce social vulnerability are individuals and communities, their involvement in disaster management should be facilitated by a group of experts from various disciplines (e.g., geophysics, civil engineering, meteorology, geography, anthropology, ecology, behavioral science and so on). Besides, a psychological approach is crucial because disaster management deals with people.

Since the questionnaire surveys were conducted in Sleman Regency and only once in the post-disaster period, spatial and temporal variations were not considered in the research. Besides, a sample size for the model development was 192. For the further research on this topic, more data considering spatial and temporal variations should be analyzed. Since PLS-SEM is designated to an exploratory multivariate analysis, the next step is a confirmatory analysis to test the model developed in this research by the covariance-based SEM (CB-SEM).

\section{REFERENCES}

Ballou, R.H. 1999, and Bussiness Logistics Management: Planning, Organizing, and Controlling the Supply Chain, Prentice Hall, Upper Saddle River, NJ.

Becker, P. 2009, Grasping the hydra: the need for a holistic and systematic approach to disaster risk reduction. Jàmbá: Journal of Disaster Risk Studies, 2(1), pp. 1-13.

Bhandari, R. B., Okada, N., Yokomatsu, M., and Ikeo, H. 2010, Building a disaster resilient community through ritual based social capital: A brief analysis of findings from the case study of Kishiwada, Annuals of Disaster Prevention Research Institute, Kyoto University, 53B, pp. 137-148.

Birkmann, J. 2006, Measuring vulnerability to promote disaster-resilient societies: Conceptual frameworks and definitions, Measuring vulnerability to natural hazards: Towards disaster resilient societies, 1, pp. 9-54.

Bollin, C., Cárdenas, C., Hahn, H., and Vatsa, K.S. 2003, Disaster risk management by communities and local governments, Inter-American Development Bank.

Bowersox, D.J., and Closs, D.J. 1996, Logistical Management: The Integrated Supply Chain Process, McGraw-Hill, New York. 
Cohen, J. 1992, A power primer, Psychological Bulletin, 112, pp.155-159.

Comfort, L., Wisner, B., Cutter, S., Pulwarty, R., Hewitt, K., Oliver-Smith, A. et al. 1999, Reframing disaster policy: the global evolution of vulnerable communities, Global Environmental Change Part B: Environmental Hazards, 1(1), pp. 39-44.

Cutter, S.L. 1996, Vulnerability to environmental hazards, Progress in Human Geography, 20(4), pp. 529-539.

Cutter, S.L., Boruff, B.J., and Shirley, W.L. 2003, Social vulnerability to environmental hazards, Social Science Quarterly, 84(2), pp. 242-261.

Directorate General of Water Resources (DGWR). 2001, Mt. Merapi and Mt. Semeru Volcanic Disaster Countermeasures Project: Review Master Plan Study, Jakarta, DGWR, Ministry of Public Works Indonesia.

Directorate General of Water Resources (DGWR). 2009, Study on the institution and community development at Mt. Merapi Area, Jakarta, DGWR, Ministry of Public Works Indonesia.

Federal Emergency Management Agency. 1998, Planning for Post-Disaster Recovery and Reconstruction (FEMA 421), Washington D.C., FEMA, USA.

Fukushima, M. and Matsumoto, T. 2007, Study on formation factor of local environmental power by using covariance structure analysis, Environmental Systems Research, Japan Society of Civil Engineers, 35, pp. 327-332.

Hair, J.F., Ringle, C.M. and Sarstedt, M. 2011, PLSSEM: Indeed a silver bullet, Journal of Marketing Theory and Practice, 19, pp. 139-151.

Hair, J.F., Hult, G.T.M., Ringle, C.M. and Sarstedt, M. 2013, A Primer on Partial Least Squares Structural Equation Modeling (PLS-SEM), California: SAGE Publications, USA.

Hair, J.F., Hult, G.T.M., Ringle, C.M. and Sarstedt, M. 2014, A Primer on Partial Least Squares Structural Equation Modeling (PLS-SEM), California: SAGE Publications, USA.

Hashiue, K., Kikuchi, A., Fujii, S., and Kitamura, R. 2003, The analysis of people's importance believes about administrative and self-help measures for disaster prevention, Infrastructure Planning Review, 20, pp. 337-344.
Henseler, J., Ringle, C. M., and Sinkovics, R. R. 2009, The Use of Partial Least Squares Path Modeling in International Marketing, Advances in International Marketing, 20.

Henseler, J., Ringle, C.M., and Sarstedt, M. 2012, Using partial least squares path modeling in advertising research: basic concepts and recent issues, in Okazaki, S., Handbook of research on international advertising, Edward Elgar Publishing, Glos, pp. 252276.

Johnson, J.C., Wood, D.F., Wardlow, D.L., and Murphy, P.R. Jr. (ed), 1999, Contemporary Logistics, Prentice Hall, Upper Saddle River, USA.

Law of Republic Indonesia, 2007, Undang-Undang No 24, Ministry of Law, Jakarta.

O'Brien, G., O'Keefe, P., Rose, J., and Wisner, B. 2006, Climate change and disaster management, Disasters, 30(1), pp. 64-80.

Oliver-Smith, A. 1999, 'What is a disaster?: anthropological perspectives on a persistent question', in Hoffman, S. M. (ed.), The angry earth: disaster in anthropological perspective, Routledge, New York, pp. 18-34.

Paton, D. 2003, Disaster preparedness: a socialcognitive perspective, Disaster Prevention and Management: An International Journal, 12(3), pp. 210-216.

Paton, D. and Johnston, D. 2001, Disasters and communities: vulnerability, resilience and preparedness, Disaster Prevention and Management: An International Journal, 10(4), pp. 270-277.

Paton, D., Bajek, R., Okada, N., and McIvor, D. 2010, Predicting community earthquake preparedness: a cross-cultural comparison of Japan and New Zealand, Natural Hazards, 54(3), pp.765-781.

Perry, M., 2007. Natural disaster management planning. International Journal of Physical Distribution and Logistics Management, 37, 409-433.

Schneiderbauer, S. and Ehrlich, D. 2006, Social levels and hazard (in) dependence in determining vulnerability, in Birkmann, J. (ed.), Measuring vulnerability to natural hazards: Towards disaster resilient societies, UNU-Press, Tokyo, pp. 78-102.

Tatsuki, S., Hayashi, H., Yamori, K., Noda, T., Tamura, K., and Kimura, R. 2004, Model Building and Testing of Long-Term Life Recovery Processes of the Survivors of the 1995 Kobe earthquake: Structural 
Equation Modeling (SEM) of the 2003 Hyogo Prefecture Life Recovery Survey, Journal of Institute of Social Safety Science, 6, pp. 251-260.

Thomas, J.C., 1995, Public Participation in Public Decisions: New Skills and Strategies for Public Managers, Wiley, New York, USA.

United Nations Development Program (UNDP). 2004, Reducing disaster risk, a challenge for development, New York, UNDP.

United Nations, International Strategy for Disaster Reduction (UNISDR). 2004, Living with risk: a global review of disaster reduction initiatives, Geneva,
United Nations, International Strategy for Disaster Reduction.

United Nations, International Strategy for Disaster Reduction (UNISDR). 2009, UNISDR terminology on disaster risk reduction, Geneva, United Nations, International Strategy for Disaster Reduction.

United Nations, International Strategy for Disaster Reduction (UNISDR). 2017, Terminology, accessed August 8, 2017, https://www.unisdr.org/we/inform/ terminology 
[this page is intentionally left blank] 